\title{
High-Precision Numerical Simulation on the Cyclic High-Pressure Water Slug Injection in a Low-Permeability Reservoir
}

\author{
Jie Zhan $\mathbb{D}^{\mathbb{1}},{ }^{1,2}$ Chao Fan $\mathbb{D}^{1,2}$ Xianlin Ma $\mathbb{D}^{1,2}$ Zigang Zheng $\mathbb{D}^{3},{ }^{3}$ Zezhong Su $\mathbb{D}^{1,2}$ \\ and Zhihao Niu $\mathbb{i D}^{1,2}$ \\ ${ }^{1}$ School of Petroleum Engineering, Xi'an Shiyou University, Xi'an 710065, China \\ ${ }^{2}$ Engineering Research Center of Development and Management for Low to Ultra-Low Permeability Oil \& Gas Reservoirs in \\ West China, Ministry of Education, Xi'an Shiyou University, Xi'an 710065, China \\ ${ }^{3}$ Petroleum Exploration and Development Research Institute, PetroChina Changqing Oilfield Company, Xi'an 710018, China
}

Correspondence should be addressed to Jie Zhan; zhanjie@xsyu.edu.cn and Xianlin Ma; xianlinm@126.com

Received 8 May 2021; Accepted 12 July 2021; Published 30 July 2021

Academic Editor: Jianchao Cai

Copyright ( 92021 Jie Zhan et al. This is an open access article distributed under the Creative Commons Attribution License, which permits unrestricted use, distribution, and reproduction in any medium, provided the original work is properly cited.

The paper presents a novel waterflooding technique, coupling cyclic high-pressure water slug injection with an asynchronous injection and production procedure, to address the inefficient development of low-permeability oil reservoir in Shengli Oilfield, a pilot test with 5-spot well pattern. Based on the first-hand data from the pilot test, the reservoir model is established. With an in-depth understanding of the mechanism of the novel waterflooding technique, different simulation schemes are employed to screen the best scheme to finely investigate the historical performance of the pilot test. The production characteristics of the pilot test are both qualitatively and quantitatively investigated. It is found that the novel waterflooding technique can provide pressure support within a short period. And the formation around the injector is significantly activated and deformed. Once passing the short stage of the small elastic deformation, the reservoir immediately goes through the dilation deformation accompanied with the opening of microfractures so that the reservoir properties are significantly improved, which leads to better reservoir performance. With the multicyclic dilationrecompaction geomechanical model, the impact of pressure cyclic evolution on the reservoir properties and performance under the novel waterflooding mode of cyclic high-pressure water slug injection is taken into consideration. The historical data of the pilot test is well matched. In the study, a high-precision simulation scheme for the novel waterflooding technique in low-permeability reservoirs is proposed, which provides significant technical support for further optimization of the pilot test and large-scale application of the novel waterflooding technique.

\section{Introduction}

About $38 \%$ of the global and $46 \%$ of China's oil and gas resources are of low quality mainly in low-permeability reservoirs, which need to be effectively developed to ensure sustainable development worldwide [1-4]. In recent years, with the exploration and development of unconventional oil and gas, numerous studies on the efficient development of low-permeability reservoirs have been done by many researchers [5-11]. With the application of horizontal well, multistage hydraulic fracking and acidizing, synchronous/asynchronous water injection, advanced water injection, lay- ered water injection, and other techniques, the lowpermeability reservoir is commercially and sustainably developed [12-21]. At present, water injection is still the primary method for the development of low-permeability reservoirs. But the effectiveness of water injection varies according to the formation characteristics. As to the reservoir with the development of fracture, the injected water tends to transport along the fracture, leading to water channeling and ineffective water injection. As to the low-permeability reservoir without fracture development, the poor reservoir properties with high start-up pressure gradient have a negative impact on the injectivity, such as Block A of Shengli Oilfield. 
Therefore, according to different reservoir characteristics, an effective pressure-driven system between the injector and producer needs to be established to optimize the water injection. Based on traditional water injection mode and technology, it is urgent to develop an effective water injection mode and corresponding supporting technology to improve the reservoir performance, where many researchers have conducted extensive research. Wu et al. proposed a development scheme for ultra-low-permeability reservoirs, combining cyclic water injection, volumetric stimulation, and asynchronous injection-production into a novel recovery technique [22]. A feasibility study of water injection pressure close to failure pressure for a low-permeability reservoir was conducted by Liang et al. [23]. Inspired by the idea of hydraulic fracking in shale gas reservoirs, Liu et al. proposed a development method for fractured-vuggy reservoirs, increasing the injection pressure to the failure pressure so that the connection between the well and the cavity is established to enhance reservoir performance [24]. Based on the extensive investigation and evaluation, Shengli Oilfield proposes an innovative waterflooding technique, coupling cyclic high-pressure water slug injection with an asynchronous injection and production procedure. And a pilot test is carried out with 5-spot well pattern. Various techniques, combined into a novel waterflooding mode, have been implemented to efficiently develop Block A, such as high-pressure water injection with multicycle, large injection volume, and asynchronous injectionproduction.

The paper presents a high-precision numerical simulation method for the novel waterflooding technique applied in Shengli Oilfield, including the primary mechanisms of the process. Taking the pilot test in Block A of Shengli Oilfield as an example, the reservoir model, which employs a multicycle dilation-recompaction geomechanical model to finely history-match the pilot test data, is established to quantify the evolution of reservoir properties and reservoir performance during high-pressure water slug injection. With this methodology presented in the study, not only the pilot test can be further optimized, leading to a more efficient and sustainable development, but also the feasibility of high-pressure water slug injection applied to other lowpermeability reservoirs can be quantitatively analyzed and evaluated, which promotes the development and application of high-pressure water slug injection technology in China and worldwide.

\section{Reservoir Model and Simulation Schemes}

2.1. Overview of Block A. The development of the block has started since 2014. The target formation is the third member of Shahejie Formation in the Dongying Depression, which is low-permeability lithologic reservoir with average pore throat radius of $0.39 \mu \mathrm{m}$. The average porosity of the reservoir is $20 \%$. And the average permeability is $5 \mathrm{md}$. Before the pilot test of high-pressure water slug injection, the pilot site is depleted for several years with the cumulative oil production of $0.63 \times 10^{4} \mathrm{t}$, the cumulative water production of $0.39 \times 10^{4} \mathrm{~m}^{3}$, and cumulative water injection of $0.27 \times 10^{4}$ $\mathrm{m}^{3}$. The reservoir is depleted without any energy supplement for years, leading to a rapid decline in productivity. Before the pilot test of high-pressure water slug injection, only one well is producing with an average daily liquid production of $1.3 \mathrm{t}$, daily oil production of $1.0 \mathrm{t}$, and water cut of $21.2 \%$. With the high-pressure water slug injection for about two months, the cumulative injection water of four slugs is 6.0 $\times 10^{4} \mathrm{~m}^{3}$. The cumulative oil/water production of the pilot test is $373.7 \mathrm{t}$ and $322 \mathrm{~m}^{3}$, respectively. The pilot test performs as expected. But there is an urgent need to clarify the mechanism of the process and establish a systematic understanding of the novel technique. Meanwhile, the corresponding simulation technology for the novel waterflooding mode needs to be developed to promote the efficient development of low-permeability reservoirs with the high-pressure water slug injection.

2.2. High-Pressure Water Slug Injection. The lowpermeability reservoir with poor reservoir properties results in relatively high seepage resistance and start-up pressure. High-pressure water injection not only reduces the negative impact arising from high seepage resistance and start-up pressure, leading to the increase of the injectivity, but also overcomes the additional resistance induced by capillary force and improves the recovery, which effectively overcomes the related problems on low water injectivity and oil recovery and comprehensively improves the low-permeability reservoir performance from both injection and production sides. With the depletion of the reservoir, the reservoir pressure decreased rapidly. Compared with the traditional water injection mode, the high-pressure water slug injection with a large injection volume can provide the formation with tremendous energy within a short period. With the highpressure water slug injection in low-permeability reservoirs, the $\mathrm{BHP}$ of the injector is close to the failure pressure. And the formation around the injector is effectively activated with dilation. With the opening of microfractures around the injector, the reservoir properties (permeability and porosity) are significantly improved, which leads to better reservoir performance.

2.3. Dilation-Recompaction Model. The application of highpressure water slug injection leads to high water injectivity within a short period. The conventional numerical reservoir model has several limitations to deal with the novel waterflooding mode. Firstly, high-pressure injection with large injection volume results in the rapid BHP build-up (BHP higher than failure pressure), which does not align with the actual situation (BHP close to failure pressure). Meanwhile, the rapid pressure build-up will lead to poor numerical stability of the model. Secondly, the conventional simulation method cannot objectively represent the piecewise and path-dependent evolution of reservoir properties with the pore pressure. In a word, the conventional way cannot objectively simulate activated and significantly deformed formation due to the high-pressure water slug injection.

In this study, the multicyclic dilation-recompaction geomechanical model is introduced to make up for the limitations of the conventional simulation method and establish the simulation technique for the high-pressure water slug 
injection, finely simulating the pilot test. The multicyclic dilation-recompaction geomechanical model, also referred as the Beattie-Boberg model, was proposed by Beattie et al. for the first time to depict the cyclic deformation of rock with pressure under cyclic steam stimulation (CSS). The model quantitatively characterizes the piecewise and pathdependent evolution of porosity with reservoir pressure, as shown in Figure 1 [25-29].

With the injection of huge amounts of fluids, the pore pressure increases from the initial reservoir pressure, and the effective stress decreases. The rock behaves elastically, and the porosity changes slightly with the pressure (from point $a$ to point $b$ in Figure 1). If the pressure decreases from a point on the elastic curve at a certain moment, porosity follows a reversible elastic compaction curve to the initial reservoir porosity (from point $b$ to point $a$ in Figure 1). As pressure continues to increase to exceed the dilation pressure $\left(P_{\mathrm{D}}\right)$, dilation of the reservoir occurs. Then, porosity follows the irreversible dilation curve until either pressure declines or the maximum porosity $\left(\phi_{\max }\right)$ is reached (from point $b$ to point $c$ in Figure 1). In the model, the maximum porosity $\left(\phi_{\max }\right)$ is related to the $r_{\mathrm{at}}$, which is the maximum allowed proportional increase in porosity. The minimum allowed value of $r_{\mathrm{at}}$ is 1 . The maximum recommended value of $r_{\mathrm{at}}$ is 1.3 , which is the upper limit for $r_{\text {at }}$. Porosity increases rapidly with the increase of pressure during dilation. If pressure decreases from a point on the dilation curve, there are two stages of compaction: one is elastic compaction, and the other one is recompaction. Once the pressure begins to decline, before it reaches the recompaction pressure $\left(P_{\mathrm{R}}\right)$, porosity follows a reversible elastic compaction path (from point $c$ to point $d$ in Figure 1). As pressure decreases further till the pressure is less than the recompaction pressure $\left(P_{\mathrm{R}}\right)$, recompaction occurs. This process is irreversible (from point $d$ to point $e$ in Figure 1). The residual dilation fraction $\left(f_{\mathrm{r}}\right)$ is defined as the fraction of the total dilation that is permanent and unrecoverable. For instance, $f_{\mathrm{r}}=0$ means that the pore volume that increased from dilation could be diminished completely and $f_{\mathrm{r}}=1$ indicates that the dilation of the block is maintained definitely.

With the multicyclic injection, the rock follows the same rule but with cyclic dilation-recompaction evolution, as shown in Figure 2. When the pressure increases from a point on the recompaction curve, the reservoir follows an elastic compaction path until reaching the dilation curve. Then, the dilation occurs again, as shown in Cycle 1. If the pressure begins to decrease before the dilation pressure is reached, the reservoir undergoes reversible elastic deformation. With the decrease of the pressure, the reservoir undergoes elastic compaction or even recompaction, as shown in Cycle 2. The multicyclic dilation-recompaction geomechanical model essentially reflects that the rock property evolution follows a piecewise and path-dependent rule. In this model, the analytical relation between the porosity and pore pressure is expressed by the following equation:

$$
\phi=\phi_{\mathrm{r}} e^{\left[c\left(p-p_{\mathrm{r}}\right)\right]},
$$

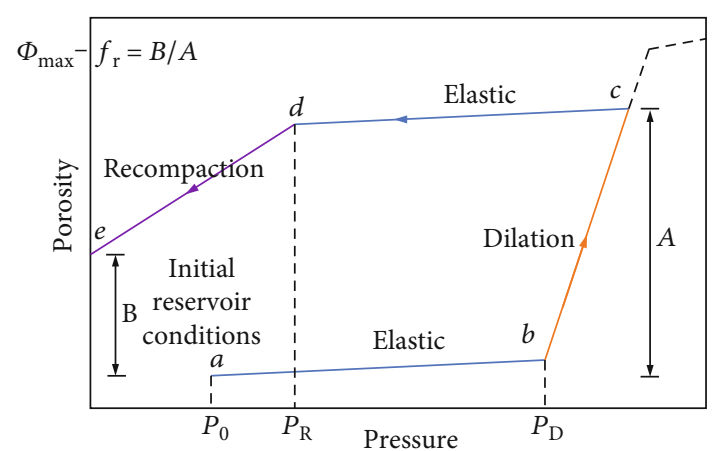

FIGURE 1: Dilation-recompaction model (modified from ref. [29]).

where $c$ is the compressibility; $p_{\mathrm{r}}$ is reference pressure; and $\phi_{r}$ is the porosity at the reference pressure.

Due to the stress sensitivity of a low-permeability reservoir, the reservoir permeability also evolves with the pressure. The analytical correlation is that the permeability evolves with the porosity which is a function of reservoir pressure [30-35]. We model the permeability change with the following analytical dilation-recompaction permeability model. The permeability is a function of fluid porosity via a permeability multiplier. Based on the equation, the change of permeability with porosity is more significant if a bigger multiplier is applied.

$$
K=K_{0} e^{\left[K_{\mathrm{MUL}}\left(\phi-\phi_{0}\right) /\left(1-\phi_{0}\right)\right]},
$$

where $K_{0}$ is the original permeability; $K_{\mathrm{MUL}}$ is a user-defined permeability multiplier; and $\phi_{0}$ is the original porosity.

With the large amounts of water being injected, the pore space is greatly expanded along with the storage of the elastic energy, so that the pore pressure increases with the decrease of the effective stress, leading to enhanced reservoir properties and better reservoir performance. The key geomechanical parameter dominating each deformation stage is the piecewise rock compressibility, to which different values are assigned based on the range of pore pressure and the direction of the pore pressure change.

2.4. Reservoir Model. Based on the CMG, a homogeneous 3D reservoir model of high-pressure water slug injection is established. The dimensions of the numerical model are $1500 \mathrm{~m}$ $\times 1950 \mathrm{~m} \times 4.5 \mathrm{~m}$, corresponding to the length, width, and thickness of the reservoir, respectively. One vertical injector and four vertical producers, which are perforated from top to the bottom of the reservoir, are simulated in the model for a 5-spot well pattern, as shown in Figures 3 and 4.6.0 $\times$ $10^{4} \mathrm{~m}^{3}$ of water is injected by four slugs for the pilot test in two months, as shown in Figure 5. The specific parameters employed in the numerical model are listed in Table 1. The specific parameters used in the dilation-recompaction model are listed in Table 2.

\section{Numerical Simulation}

Based on the numerical model established above, the highprecision simulation method suitable for the novel high- 


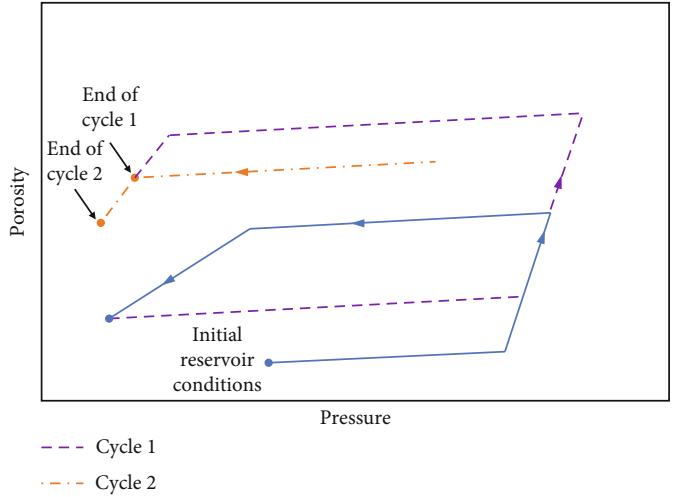

Figure 2: Multicycle process of dilation-recompaction (modified from the ref. [29]).

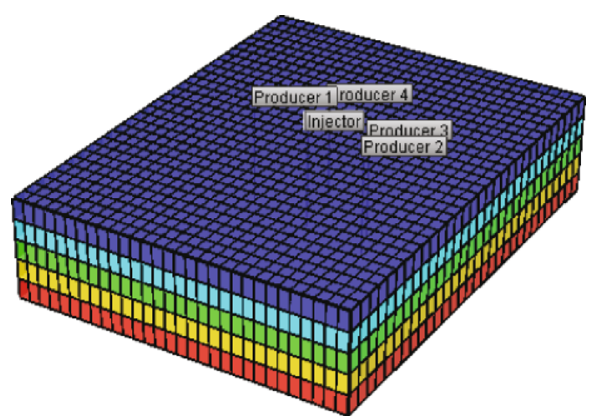

Figure 3: Three-dimensional reservoir model.

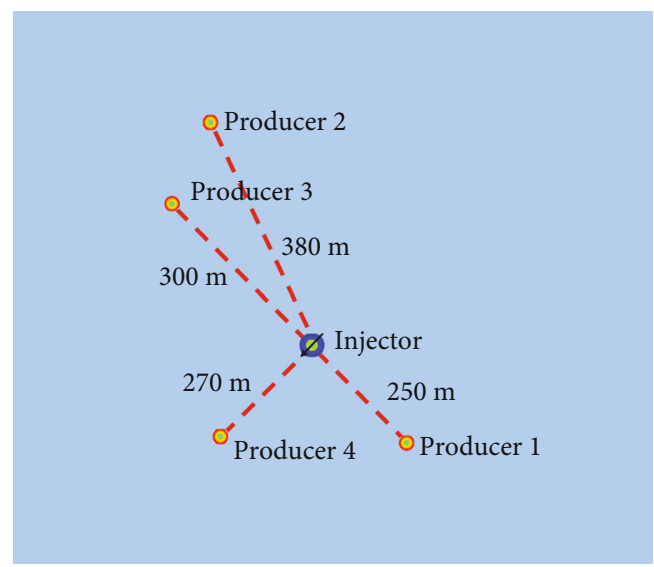

Figure 4: Display of the pilot well group.

pressure water slug injection is investigated. Then, the historical performance of the pilot test can be examined and the relevant mechanisms of the high-pressure-driven waterflooding can be quantified, which provides scientific guidance for the large-scale application of this technique.

\subsection{Numerical Simulation without Dilation-Recompaction} Model. Based on the reservoir engineering method, the compressibility coefficient of reservoir rock is inverted as $\sim 5.0 \times 10^{-3} \mathrm{Mpa}^{-1}$ with the collected pressure data from producer 4 , which indicates that the rock is highly compressible. It provides storage space for the fluid injected by the high-

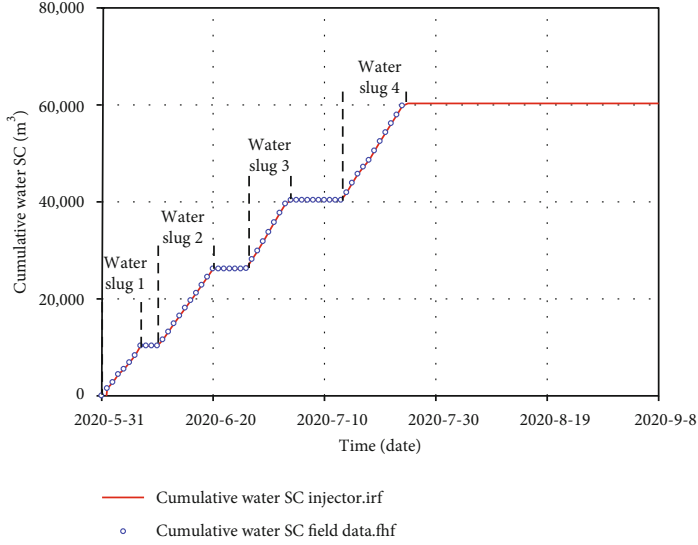

Figure 5: Cumulative water injection.

TABLE 1: List of model parameters.

\begin{tabular}{lc}
\hline Model dimensions $(\mathrm{m})$ & $1500 \times 1950 \times 4.5$ \\
Thickness $(\mathrm{m})$ & 4.5 \\
Depth $(\mathrm{m})$ & 3200 \\
Porosity & $20 \%$ \\
Permeability $(\mathrm{md})$ & 5 \\
Initial reservoir pressure $(\mathrm{MPa})$ & 28 \\
Reservoir temperature $\left({ }^{\circ} \mathrm{C}\right)$ & 123 \\
\hline
\end{tabular}

TABLE 2: Parameters used in the dilation-recompaction model.

\begin{tabular}{lc}
\hline Initial reservoir pressure $\left(P_{0}\right)(\mathrm{MPa})$ & 28 \\
Dilation pressure $\left(P_{\mathrm{D}}\right)(\mathrm{MPa})$ & 50 \\
Recompaction pressure $\left(P_{\mathrm{R}}\right)(\mathrm{MPa})$ & 30 \\
Compressibility coefficient $\left(c_{a b}\right)(1 / \mathrm{kPa})$ & $8.5 E-6$ \\
Dilation compressibility coefficient $\left(c_{b c}\right)(1 / \mathrm{kPa})$ & $3.0 E-4$ \\
Residual dilation fraction $\left(f_{\mathrm{r}}\right)$ & 0.1 \\
Maximum allowed proportional increase in porosity $\left(r_{\mathrm{at}}\right)$ & 1.3 \\
Permeability multipliers $(I / J / K)\left(K_{\mathrm{MUL}}\right)$ & 50
\end{tabular}

pressure injection scheme. Combined with the calibration of reservoir permeability and other simulation techniques, we try to match historical data. Figure 6 illustrates that oil/water production data can be well matched by this method. But the pressure cannot be matched. The results of history matching on pressure are shown in Figure $7(\mathrm{a})$, where the error cannot be ignored. The simulated pressure is much larger than the actual data. The compressibility coefficient is adjusted to reduce the gap between the simulated data and real data. The history matching on pressure tends to be better, but the results are still not good enough, as shown in Figure $7(b)$.

\subsection{Numerical Simulation with Dilation-Recompaction} Model. With an in-depth understanding of the mechanism of high-pressure water slug injection, it is recognized that 


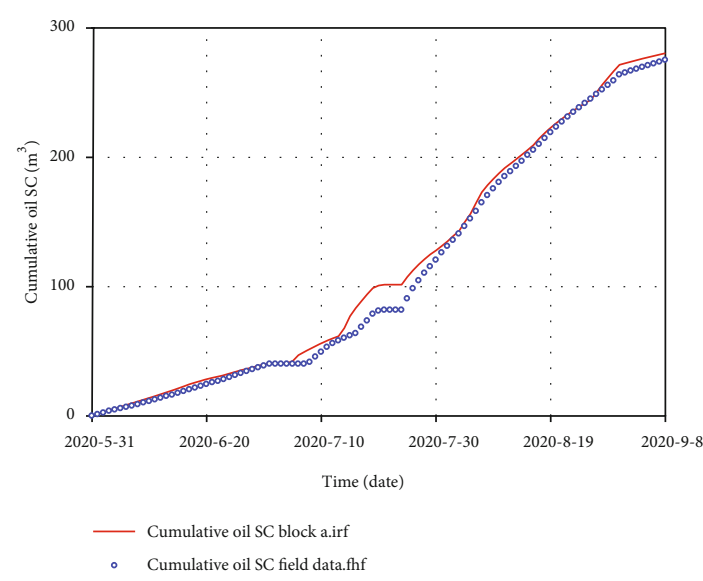

(a) Cumulative oil production

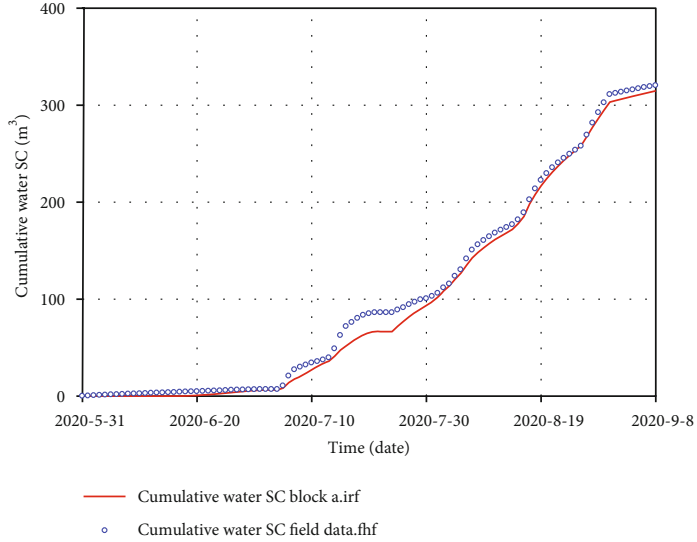

(b) Cumulative water production

FIGURE 6: History match of production data.

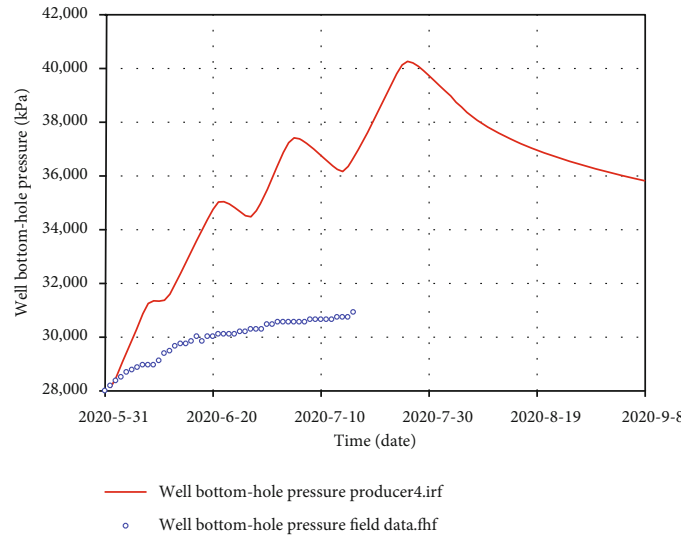

(a) With initial compressibility coefficient

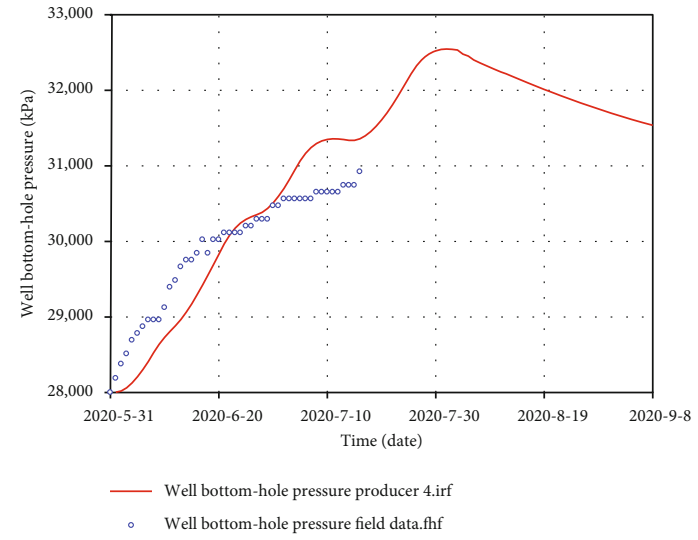

(b) With adjusted compressibility coefficient

FIGURE 7: History match of pressure: BHP of producer 4.

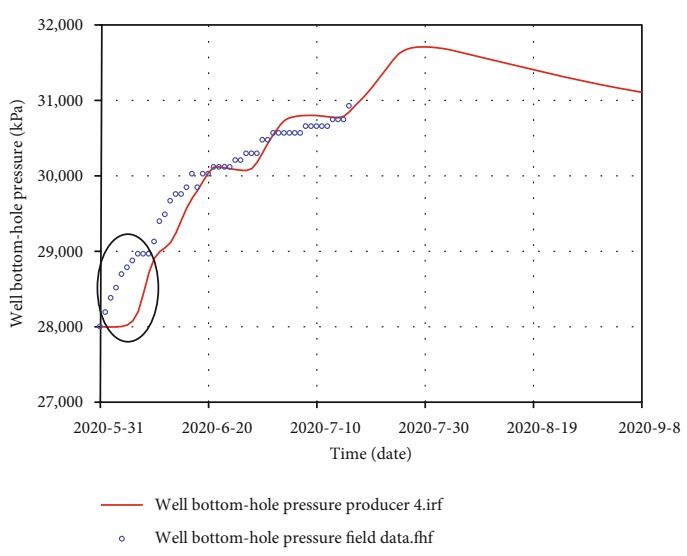

FIGURE 8: Simulation results with the dilation-recompaction model: permeability multiplier of 50 .

the reservoir properties around the injector are effectively and dynamically improved. The reservoir around the injector undergoes significant dynamic deformation. The compression coefficient of the conventional rock model is static, and it cannot represent piecewise and path-dependent change of the reservoir properties with the cyclic evolution of pressure. In other words, the conventional simulation scheme is impossible to precisely reproduce the physical process of high-pressure water slug injection, where the rock properties evolve with cyclic pressure from the elastic stage with small deformation to the dilation with large deformation. Therefore, based on the previous simulation scheme, coupled with the dilation-recompaction geomechanical model, the BHP of producer 4 can be further matched, as shown in Figure 8 . Based on the simulation method coupled with dilationrecompaction geomechanical model, historical data can be well matched, but the early part of the simulation for the pressure response is still poor.

In the system of multiphase flow in porous media, the efficiency of energy transfer is positively related to permeability. Based on the dilation-recompaction geomechanical model, three submodels are established to analyze the sensitivity of the permeability multiplier to further match the pressure. The simulation results suggest that scheme 2 is the best case to match the pressure compared with other schemes, as shown in Figure 9. The parameters of sensitivity analysis are listed in Table 3. 


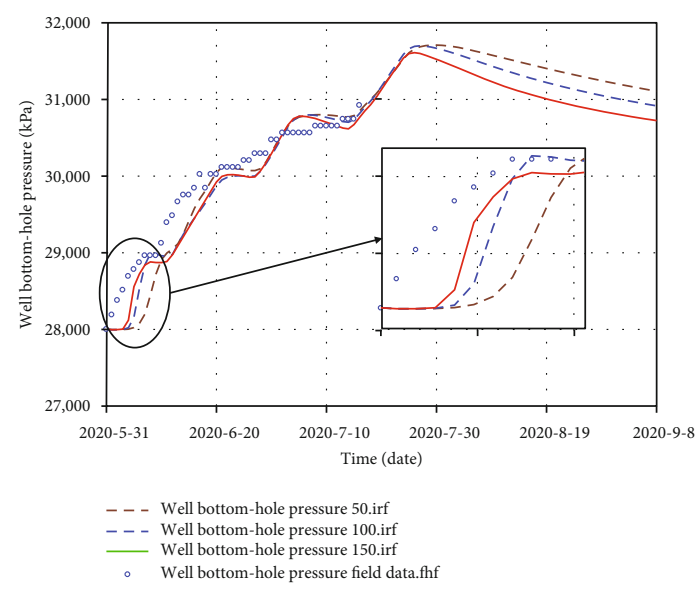

FIgURE 9: Simulation results of schemes 1-3.

3.3. Evolution of Pressure and Reservoir Properties. Based on the best case, the dynamic evolution of reservoir properties (porosity and permeability) and transient pressure behavior are finely studied.

3.3.1. The BHP Evolution of the Injector. The dynamic evolution of BHP of the injector is further studied based on the above cases. The simulation presented in Section 3.1 shows that the BHP of the injector increases continuously and periodically, as shown in Figure 10(a). This is because the conventional simulation scheme cannot objectively reflect the dynamic evolution of reservoir properties (porosity and permeability) during the high-pressure water slug injection. This simulation method, without taking the dilationrecompaction model into consideration, only characterizes the gradual reversible elastic small deformation. It cannot characterize piecewise and path-dependent deformation. With the pressure close to the failure pressure, the large deformation actually occurs and microfractures near the wellbore are activated. Due to the limitation of this simulation scheme, with the large volume of injected fluid, the elastic energy cannot spread out in time. Therefore, the pressure will continue to increase in each cycle of water slug injection, resulting in the "cyclic and continuous pressure build-up" behavior.

The simulation method presented in Section 3.2 considers the geomechanical factors and the dilationrecompaction model. It can be observed that during the high-pressure water slug injection, the BHP is relatively stable, which is kept basically around $50 \mathrm{MPa}$. Such response of BHP tends to align with the actual situation, stable and close to failure pressure. The formation energy is efficiently replenished due to the large volume of injected water within a short time. Meanwhile, the reservoir rocks are efficiently deformed. The dilation with large deformation occurs immediately after a short elastic stage with small deformation. The reservoir near the injector is effectively activated with the improved reservoir properties, providing storage space for the injected water and facilitating the diffusion of elastic energy to the producer from the injection spot. Because the pressure is easily diffused outwards from the injection spot,
TABLE 3: Sensitivity analysis.

\begin{tabular}{lc}
\hline Scheme & Permeability multiplier \\
\hline Scheme 1 & 50 \\
Scheme 2 & 100 \\
Scheme 3 & 150 \\
\hline
\end{tabular}

the pressure does not build up around the injector, facilitating the water injection. This is also the reason why $6.0 \times$ $10^{4} \mathrm{~m}^{3}$ of water can be effectively injected within a short time ( $\sim 2$ months). The large pressure fluctuation in Figure 10(b) occurs at the moment of restarting injection after the soaking. During the soaking stage, the pressure continues to diffuse outwards from the injection spot and decreases, triggering the compaction of reservoir rocks and leading to relatively poor reservoir properties at that moment. At the beginning of the next water slug injection cycle, the pressure cannot be diffused immediately, resulting in a pressure peak. Meanwhile, at the pressure peak (like the "breakdown pressure" of minifracking), due to the opening of microfractures around the injector, the reservoir properties have also been significantly improved, along with immediate spread out of peak pressure. Then, the pressure goes back to stable and smooth status. The BHP evolution without the dilationcompaction model illustrates a continuous "pressure buildup" behavior, while the BHP evolution with the dilationcompaction model clearly demonstrates a stable pressure response, accompanied by the instantaneous "breakdown pressure" response.

3.3.2. The Porosity Evolution. For the pilot test, the initial reservoir property is poor. With the injected fluid, the elastic energy cannot spread out in time, resulting in the "pressure build-up" around the injector. Due to the significant change of pressure, the dilation-recompaction model is activated. The rapid rise of pressure leads to the reservoir rock only undergoing a short elastic stage with small deformation, as shown by the highlighted segment ab in Figure 11(a). Then the dilation with large deformation is triggered by the pressure build-up, which is illustrated by the highlighted segment bc in Figure 11(a). With the dilation of reservoir rock, the porosity increases rapidly. So does the permeability. The dynamic change of porosity is shown in Figure 11. The porosity evolution of the grid block, where the injector is perforated, is consistent with the BHP evolution. With the injector undergoing a short stage of pressure rapid rise (corresponding to the short stage of elastic small deformation), the BHP is kept basically around $50 \mathrm{MPa}$ during the whole process. The rock is dilated with large deformation since the BHP reached $\sim 50 \mathrm{MPa}$. In the soaking and asynchronous production stages, the BHP of the injector decreases. The reservoir rock is elastically compacted demonstrated by the highlighted segment $\mathrm{cd}$. But the pressure does not decrease to $P_{\mathrm{R}}$, which does not trigger the recompaction. With the next cycle of water injection, the reservoir rocks undergo the next cycle of dilation-recompaction till the whole process is completed. 


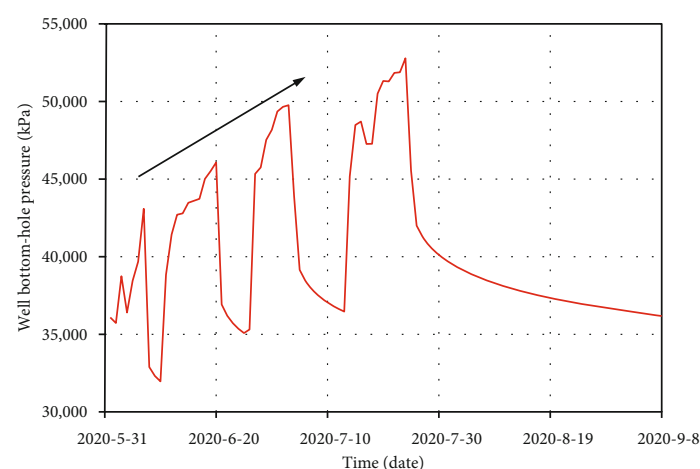

_ Well bottom-hole pressure

(a) BHP of injector without dilation-recompaction

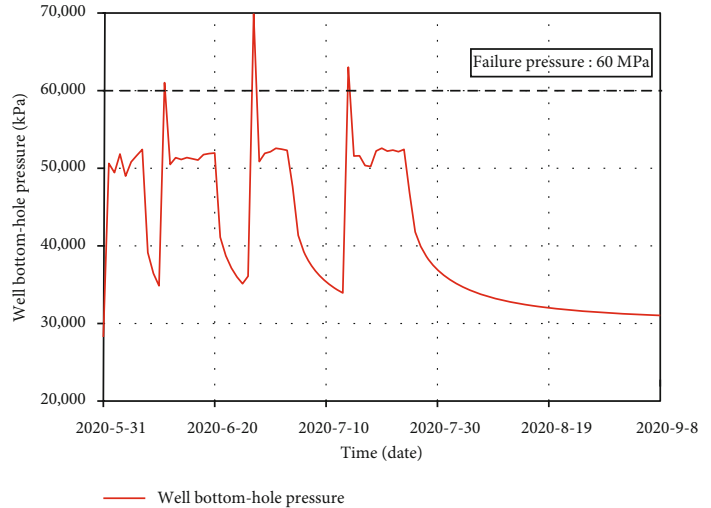

(b) BHP of injector with dilation-recompaction

Figure 10: The BHP evolution of injector.
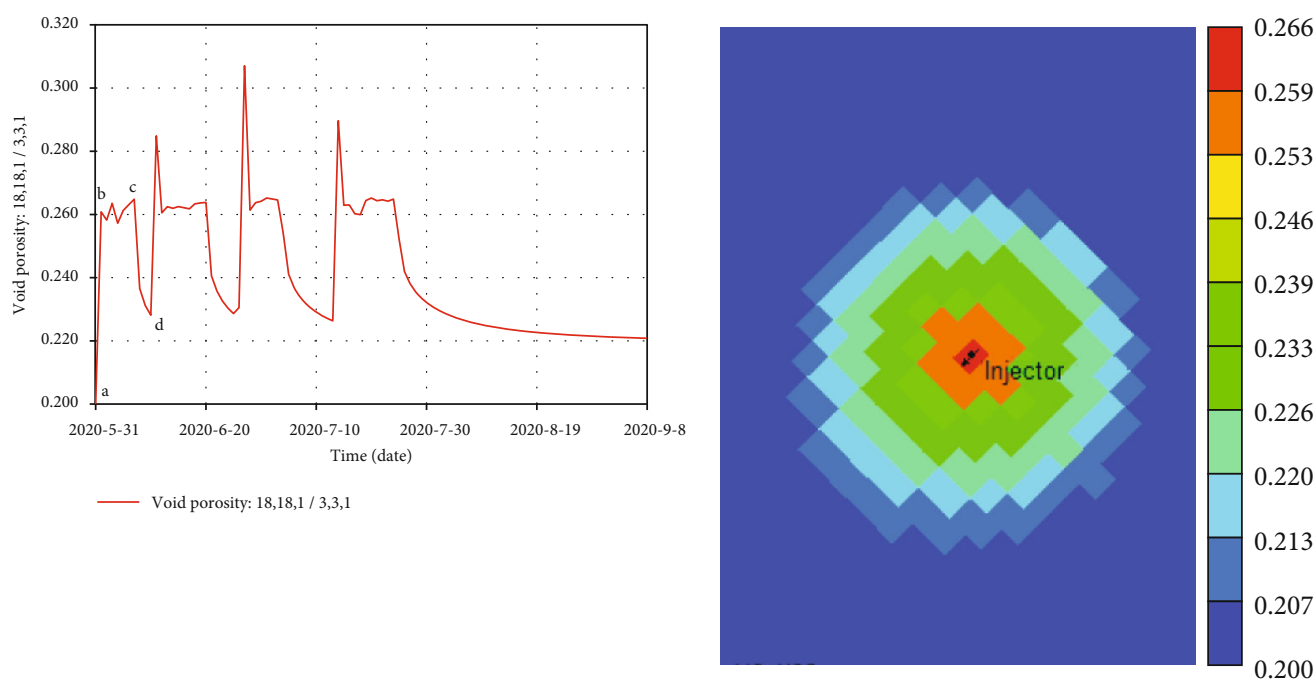

(a) Porosity evolution

(b) Dilation of porosity

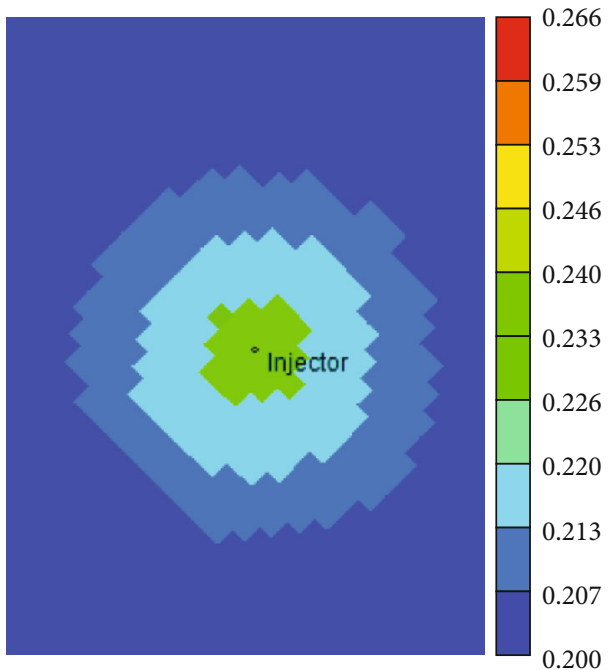

(c) Elastic compaction of porosity

Figure 11: Porosity evolution. 


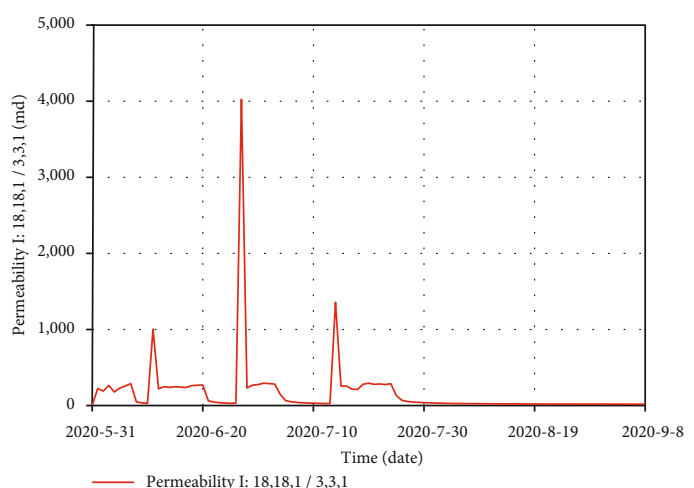

(a) Permeability evolution

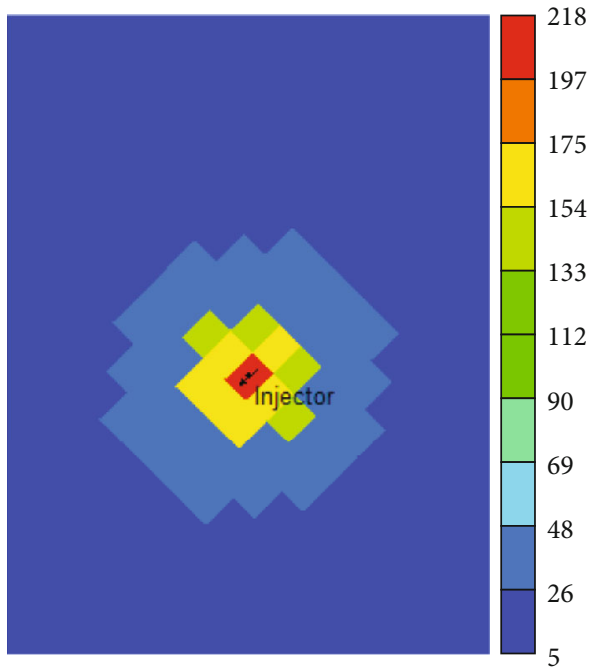

(b) Dilation of permeability

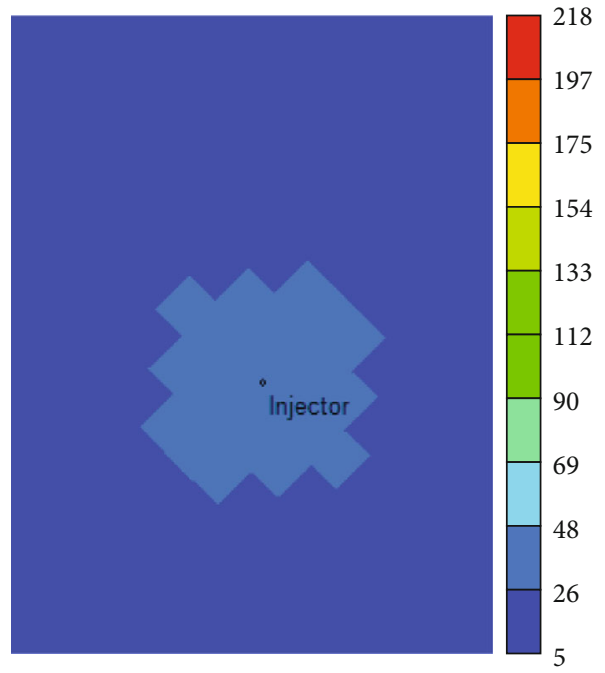

(c) Elastic compaction of permeability

Figure 12: Permeability evolution.

3.3.3. The Permeability Evolution. According to the analytical relation between porosity and permeability, permeability changes directly with porosity. The permeability evolution is closely related to the porosity evolution. The dilation and compaction stages are consistent with the corresponding evolution stages of porosity, as shown in Figure 12. The change of permeability is also consistent with pressure change. Based on the pressure evolution, it can be observed that the microfractures tend to be activated at the peak pressure, where the permeability fluctuates significantly.

\section{Conclusion}

In this paper, with the data from the pilot test, a highprecision simulation method, coupled with multicyclic dilation-recompaction geomechanical model, for the novel waterflooding technique is proposed. Meanwhile, the dynamic evolution is further studied to provide scientific guidance for the large-scale application of this technology. Based on the above research, the following conclusions are obtained:

(1) A novel waterflooding technique, coupling cyclic high-pressure water slug injection with an asynchronous injection and production procedure, for the efficient development of low-permeability reservoirs is developed.

(2) Compared with the conventional simulation method, the primary mechanism of high-pressure water slug injection can be effectively depicted with the proposed simulation method. Based on the method, the historical performance of the pilot test is reproduced. The BHP of the injector evolves into a relatively stable status with the instantaneous "breakdown pressure" response. The reservoir properties around the injector deform significantly, immediately entering 
the dilation stage with large deformation accompanied with the opening of microfractures after a short elastic small deformation.

\section{Data Availability}

Data is available upon request.

\section{Conflicts of Interest}

The authors declare no conflict of interest.

\section{Acknowledgments}

School of Petroleum Engineering in Xi'an Shiyou University is highly appreciated. This research is funded by the General Project of National Natural Science Foundation of China (Grant No. 51974253), the Youth Project of National Natural Science Foundation of China (Grant No. 52004219), the Scientific Research Program Funded by Education Department of Shaanxi Province (Grant No. 20JS117), the Natural Science Basic Research Program of Shaanxi (Grant Nos. 2020JQ-781 and 221717005), and the Graduate Student Innovation and Practical Ability Training Program of Xi'an Shiyou University (Grant Nos. YCS21113089 and YCS21111002).

\section{References}

[1] H. Wang, F. Ma, X. Tong et al., "Assessment of global unconventional oil and gas resources," Petroleum Exploration and Development, vol. 43, no. 6, pp. 925-940, 2016.

[2] W. Hu, Y. Wei, and J. Bao, "Development of the theory and technology for low permeability reservoirs in China," Petroleum Exploration and Development, vol. 45, no. 4, pp. 685697, 2018.

[3] Q. Wang and X. Song, "Forecasting China's oil consumption: a comparison of novel nonlinear-dynamic grey model (GM), linear GM, nonlinear GM and metabolism GM," Energy, vol. 183, pp. 160-171, 2019.

[4] F. Song, L. Bo, S. Zhang, and Y. Sun, "Nonlinear flow in low permeability reservoirs: modelling and experimental verification," Advances in Geo-Energy Research, vol. 3, no. 1, pp. 76$81,2019$.

[5] Q. Lei, W. Xiong, J. Yuan, S. Gao, and Y. Wu, "Behavior of flow through low-permeability reservoirs," in Europec/EAGE Conference and Exhibition, OnePetro, June, 2008.

[6] S. A. Holditch, "Unconventional oil and gas resource development-let's do it right," Journal of Unconventional Oil and Gas Resources, vol. 1, pp. 2-8, 2013.

[7] W. Wang, D. Zheng, G. Sheng, Q. Zhang, and Y. Su, “A review of stimulated reservoir volume characterization for multiple fractured horizontal well in unconventional reservoirs," Advances in Geo-Energy Research, vol. 1, no. 1, pp. 54-63, 2017.

[8] J. Cai and X. Hu, Petrophysical Characterization and Fluids Transport in Unconventional Reservoirs, Elsevier, 2019.

[9] X. Yin, S. Jiang, Y. Li et al., "Impact of pore structure and clay content on the water-gas relative permeability curve within tight sandstones: a case study from the LS block, eastern Ordos Basin, China," Journal of Natural Gas Science and Engineering, vol. 81, p. 103418, 2020.
[10] Y. Cao, M. Tang, Q. Zhang, J. Tang, and S. Lu, "Dynamic capillary pressure analysis of tight sandstone based on digital rock model," Capillarity, vol. 3, no. 2, pp. 28-35, 2020.

[11] Y. Tian, O. Uzun, Y. Shen et al., "Feasibility study of gas injection in low permeability reservoirs of Changqing oilfield," Fuel, vol. 274, p. 117831, 2020.

[12] S. D. Joshi, "A review of horizontal well and drainhole technology," in SPE annual technical conference and exhibition, OnePetro, September 1987.

[13] F. Ma, J. Hu, J. Zhuang, Q. Shi, and Q. Wu, "Advanced water injection in low permeability reservoir of block Xin119," Special Oil \& Gas Reservoirs, vol. 3, 2005.

[14] S. Morsy, J. J. Sheng, and M. Y. Soliman, "Improving hydraulic fracturing of shale formations by acidizing," in SPE Eastern Regional Meeting, OnePetro, August 2013.

[15] C. Liu, H. Liu, Y. Zhang, D. Deng, and H. Wu, "Optimal spacing of staged fracturing in horizontal shale-gas well," Journal of Petroleum Science and Engineering, vol. 132, pp. 86-93, 2015.

[16] S. Mu and M. Hb, "Sandstone matrix acidizing knowledge and future development," Journal of Petroleum Exploration and Production Technology, vol. 7, no. 4, pp. 1205-1216, 2017.

[17] Y. He, Z. Chai, J. Huang, P. Li, S. Cheng, and J. Killough, "Simulation of inter-fracture injection and production in tight reservoirs based on compartmental embedded discrete fracture model," in SPE Reservoir Simulation Conference, OnePetro, March 2019.

[18] O. SalahEldin Hussien, K. A. Elraies, A. Almansour, H. Husin, A. Belhaj, and L. Ern, "Experimental study on the use of surfactant as a fracking fluid additive for improving shale gas productivity," Journal of Petroleum Science and Engineering, vol. 183, p. 106426, 2019.

[19] F. Zhang, B. Damjanac, and S. Maxwell, "Investigating hydraulic fracturing complexity in naturally fractured rock masses using fully coupled multiscale numerical modeling," Rock Mechanics and Rock Engineering, vol. 52, no. 12, pp. 51375160, 2019.

[20] C. Wang, Z. Huang, and Y. Wu, "Coupled numerical approach combining X-FEM and the embedded discrete fracture method for the fluid-driven fracture propagation process in porous media," International Journal of Rock Mechanics and Mining Sciences, vol. 130, p. 104315, 2020.

[21] H. Feng, "Feasibility study on reservoir layered injection in Sabei Development Zone," IOP Conference Series: Earth and Environmental Science, vol. 558, no. 2, p. 22074,, 2020.

[22] Z. Wu, L. Li, and Y. Yan, “The new development mode of volume fracturing and imbibition in ultra-low permeability reservoirs," Fault block oil and gas fields, vol. 26, no. 4, pp. 491-494, 2019.

[23] C. Liang, W. Liu, and Y. Shi, "Feasibility of near-fracture pressure water injection in low permeability reservoirs - - taking Beishiliu reservoir in Beisantai oilfield as an example," Xinjiang petroleum geology, vol. 32, no. 2, pp. 153-156, 2011.

[24] P. Liu, C. Li, and L. Jiang, "Research and application of water injection by imitating bottom water and fracturing in faultkarst carbonate reservoirs," Reservoir Evaluation and Development, vol. 10, no. 2, pp. 54-59, 2020.

[25] A. Settari and J. M. Raisbeck, "Analysis and numerical modeling of hydraulic fracturing during cyclic steam stimulation in oil sands," Journal of Petroleum Technology, vol. 33, no. 11, pp. 2201-2212, 1981. 
[26] Y. Ito, "The introduction of the microchanneling phenomenon to cyclic steam stimulation and its application to the numerical simulator (sand deformation concept)," SPE Journal, vol. 24, no. 4, pp. 417-430, 1984.

[27] J. K. Dietrich, "Cyclic steaming of tar sands through hydraulically induced fractures," SPE Reservoir Evaluation \& Engineering, vol. 1, no. 3, pp. 217-229, 1986.

[28] W. D. Pethrick, E. S. Sennhauser, and T. G. Harding, "Numerical modelling of cyclic steam stimulation in Cold Lake oil sands," Journal of Canadian Petroleum Technology, vol. 27, no. 6, 1988.

[29] C. I. Beattie, T. C. Boberg, and G. S. McNab, "Reservoir simulation of cyclic steam stimulation in the Cold Lake oil sands," in SPE California Regional Meeting, OnePetro, April 1989.

[30] N. H. Kilmer, N. R. Morrow, and J. K. Pitman, "Pressure sensitivity of low permeability sandstones," Journal of Petroleum Science and Engineering, vol. 1, no. 1, pp. 65-81, 1987.

[31] R. A. Farquhar, B. G. D. Smart, A. C. Todd, D. E. Tompkins, and A. J. Tweedie, "Stress sensitivity of low-permeability sandstones from the Rotliegendes sandstone," in SPE annual technical conference and exhibition, OnePetro, October 1993.

[32] X. Huang, Application of dilation-recompaction model in hydraulic fracturing simulation [M.S thesis], University of Calgary, Calgary, 2015.

[33] X. Huang, J. Wang, S. Chen, and I. D. Gates, "A simple dilation-recompaction model for hydraulic fracturing," Journal of Unconventional Oil and Gas Resources, vol. 16, pp. 6275, 2016.

[34] R. Gao, X. Wang, Z. Yang et al., "Application of dilationrecompaction model in fracturing optimisation in tight oil reservoir," in International Petroleum Technology Conference, OnePetro, March 2019.

[35] B. Y. Jamaloei, "Impact of formation dilation-recompaction on cyclic steam stimulation," SPE Reservoir Evaluation \& Engineering, vol. 24, no. 1, pp. 98-126, 2021. 